\title{
Evaluation of the Frequency and Intensity of Osmophobia Between Headache Attacks in Migraine Patients Through an Osmophobia Diary
}

\author{
Raimundo Pereira Silva-Neto
}

\begin{abstract}
Background: Our objective was to determine the frequency and intensity of osmophobia between headache attacks in migraine patients through an osmophobia diary.

Methods: Patients with migraine without aura or with episodic tension-type headache (ETTH), diagnosed according to the diagnostic criteria of the International Classification of Headache Disorders, third edition (beta version) (ICHD-3 $\beta$ ), were interviewed about osmophobia between headache attacks.
\end{abstract}

Results: We studied 200 patients with migraine without aura and 200 with ETTH. Osmophobia between headache attacks was restricted to migraine patients $(48 / 200,24.0 \%)$. The osmophobia diary showed a frequency of osmophobia between attacks of $15.6 \pm 6.8$ days $(95 \%$ CI: 13.7 - 17.7) in the 30 -day evaluation period and in $62.5 \%(30 / 48)$ of migraine patients who presented this symptom, the frequency was greater than 15 days. The intensity ranged from severe to very severe in $61.5 \%$ (460/748) of all episodes of osmophobia. Osmophobia index was equal to $42.3 \pm 17.93$ (95\% CI: 37.2 - 47.4).

Conclusion: An osmophobia diary could be considered as a potentially valuable tool to be applied and tested in later studies to evaluate the frequency and intensity of osmophobia between headache attacks in migraine patients.

Keywords: Headache; Migraine; Osmophobia; Diary

\section{Introduction}

Osmophobia is defined as intolerance to odors and it is associated to primary headaches, particularly to migraine with or without aura $[1,2-7]$ and it may be present in tension-type headache $[5,8-11]$. The literature of its occurrence in second-

Manuscript accepted for publication March 24, 2015

Center of Neurology and Headache of Piaui, Teresina, Brazil.

Email: netoesperantina@terra.com.br

doi: http://dx.doi.org/10.14740/jnr323w ary headaches is very scarce [12].

There is a significant association between odors and primary headaches. They are triggers of headache attacks $[1,13$, 14] or intolerance factor (osmophobia), both during and between the headache attacks $[2,8,15]$. They are used to differentiate migraine and headache tension-type $[3,8,16]$. Therefore, studies on osmophobia present more significant results when we use these two comparison groups.

The prevalence of osmophobia during an attack in migraine patients ranges from $20.0 \%$ to $81.7 \%$ [2, 4-7, 8, 10 , $17,18]$. However, osmophobia may be present in the absence of pain (period between attacks) $[2,3,8,9,15,17,19,20]$. According to the diagnostic criteria of the International Classification of Headache Disorders, third edition (beta version) (ICHD-3 $\beta$ ), patients with migraine have nausea and/or vomiting or photophobia and phonophobia during headache. Despite the high prevalence of osmophobia during the attacks, it does not meet the diagnostic criteria for migraine [21].

In some patients, osmophobia is so severe that it hinders the performance of their professional activities, especially in those who work in environments with strong odors, such as in perfumery, gas station and the selling of insecticide or beauty products [13].

There are few studies on osmophobia between headache attacks in migraine patients. None of these publications describe the osmophobia characteristics, such as intensity and frequency. If these osmophobia characteristics were recorded daily by patients, they would help in understanding these patients' disease.

Therefore, the aim of this study was to determine the frequency and intensity of osmophobia between headache attacks in migraine patients, through an osmophobia diary.

\section{Patients and Methods}

\section{Study design and patients}

This was a prospective study with comparison of groups. The study population comprised a non-random and convenience sampling, consisting of the first 200 patients with migraine without aura and 200 patients with episodic tension-type headache (ETTH) (comparison group) in our Headache Center. All patients were diagnosed and treated by a single headache spe- 


\begin{tabular}{|c|c|c|c|c|c|c|c|c|c|c|c|c|c|c|c|c|c|c|c|c|c|}
\hline \multicolumn{22}{|l|}{ Name: } \\
\hline \multicolumn{22}{|c|}{ INSTRUCTIONS FOR COMPLETING THE DIARY: } \\
\hline \multirow{2}{*}{\multicolumn{22}{|c|}{$\begin{array}{l}\text { Days with headache: marck with an 'X' the box corresponding to the day he/she felt pain; } \\
\text { Days with osmophobia: marck with an 'X' the box corresponding to the day he/she felt intolerance to some smell (pleasant or unpleasant); } \\
\text { Intensity of osmophobia: even if there are variations in the intensity of osmophobia, note only the highest intensity during the day; }\end{array}$}} \\
\hline & & & & & & & & & & & & & & & & & & & & & \\
\hline \multicolumn{22}{|c|}{ Total: at the end of each month, add the number of episodes of osmophobia and the number of times that theses episodes were mild, moderate, severe or very severe. } \\
\hline \multicolumn{15}{|c|}{ Month: January } & \multicolumn{7}{|c|}{ Year: 2014} \\
\hline & 1 & 23 & 4 & 5 & 6 & 78 & 391 & 101 & 111213 & 1314 & 151 & 16171 & 1819 & 92021 & 2223 & 2425 & 262 & 2728 & 32930 & 3031 & Total \\
\hline $\begin{array}{l}\text { Days with } \\
\text { headache }\end{array}$ & & & $\times$ & & & & & & & $\times$ & & & & & $\times \times$ & & & & & & 5 \\
\hline $\begin{array}{l}\text { Days with } \\
\text { osmophobia }\end{array}$ & & $x$ & & & & $x$ & & $x$ & & & $x$ & & $x$ & & & & $x$ & & & $x$ & 7 \\
\hline Mild & & & & & & & & $x$ & & & & & & & & & & & & & $1 \times 1=1$ \\
\hline Moderate & & $x$ & & & & & & & & & & & & & & & & & & & $1 \times 2=2$ \\
\hline Severe & & & & & & $x$ & & & & & & & $x$ & & & & $x$ & & & $\times$ & $4 \times 3=12$ \\
\hline Very severe & & & & & & & & & & & $\times$ & & & & & & & & & & $1 \times 4=4$ \\
\hline \multicolumn{14}{|c|}{ Days with osmophobia } & 6 & & osmophot & bbia ind & & & 19 & \\
\hline
\end{tabular}

Figure 1. The osmophobia diary.

cialist.

\section{Inclusion and exclusion criteria}

Patients aged between 18 and 60 years, with migraine without aura or tension-type headache, according to the diagnostic criteria of the ICHD-3 $\beta$ [21], who have experienced headache in the last 6 months, but with a frequency of less than 15 days per month were included in the study.

In order to obtain consistent and valid data, the study excluded, the association between migraine and tension-type headache, concomitantly or at different times, the presence of other primary or secondary headaches, the presence of associated diseases (e.g., rhinosinusitis, skull base fracture, olfactory groove meningioma, Parkinson's disease, Alzheimer's disease, multiple sclerosis and temporal lobe epilepsy) or the use of medications (e.g., barbituric acid, methoxypsoralen and pyrazinamide) that might impair olfaction, and pregnant women.

\section{Data collection}

The patients underwent a thorough standard medical history performed by a headache specialist (a single doctor performed all interviews) to record the typical characteristics of their pain over the past six months. Having met the criteria for inclusion and exclusion, patients were invited to participate in the study by signing the Informed consent form. Then, a structured interview based on a questionnaire to investigate the research objectives was done. Excluded at this stage were uncooperative patients or those who answered the interview incompletely.

The interview consisted of questioning the patients about intolerance to any odor during the period between headache attacks. A form was filled out daily for 30 days by the patients who were intolerant to some odor. This form was similar to the headache diary and we called it osmophobia diary. In this diary, patients filled the frequency and intensity of osmophobia in the pain free period, as shown in Figure 1.
Regarding frequency, osmophobia was classified as absent (no occurrence), frequent ( $\geq 1$ to $<15$ days/month) or very frequent ( $\geq 15$ days/month). We used a visual analog scale (VAS) to classify the intensity of osmophobia as VAS $1-4$ (mild), VAS 5 - 7 (moderate), VAS 8 - 9 (severe), and VAS 10 (very severe). There are no previous studies referring the categorization of frequency (absent, frequent or very frequent) and intensity (mild, moderate, severe or very severe) of osmophobia. Up to now, there is no known use of the EVA to assess osmophobia. However, these same parameters are used to evaluate headache. Thus, we have decided also to use them to assess osmophobia.

The interview conducted by a headache specialist to diagnose the disease corresponded to the last 6 months, but the osmophobia diary was filled out by each patient based on the following 30 days.

During the follow-up of these patients, scores 1, 2, 3 and 4 were assigned, respectively, for mild, moderate, severe and very severe intensities over a period of 30 days. Then we multiplied the four intensity groups by its respective scores and the

Table 1. Distribution of Sex and Age According to Diagnosis of 200 Patients With Migraine Without Aura and 200 With Episodic Tension-Type Headache

\begin{tabular}{|c|c|c|c|}
\hline \multirow{2}{*}{ Variables } & \multicolumn{2}{|c|}{ Diagnostic } & \multirow{2}{*}{$P$ value } \\
\hline & MWA & ЕTTH & \\
\hline Sex & & & $<0.001 *$ \\
\hline Female (n, \%) & $182(91.0)$ & 37 (18.5) & \\
\hline Male (n, \%) & $18(9.0)$ & $163(81.5)$ & \\
\hline Age (years) & & & $0.008^{\dagger}$ \\
\hline Mean & $37.3(9.0)$ & $40.0(10.4)$ & \\
\hline $95 \%$ CI & $36.0-38.6$ & $38.5-41.4$ & \\
\hline
\end{tabular}

MWA: migraine without aura; ETTH: episodic tension-type headache; $\mathrm{Cl}$ : confidence interval. ${ }^{*} \mathrm{P}$ value based on the Chi-square test; ${ }^{\dagger} \mathrm{P}$ value by the Mann-Whitney test for average difference test between averages of unpaired samples. 
Table 2. Presence of Osmophobia Between Headache Attacks in 200 Patients With Migraine Without Aura and 200 With Episodic Tension-Type Headache

\begin{tabular}{|c|c|c|c|c|c|}
\hline \multirow{3}{*}{ Symptom } & \multicolumn{4}{|c|}{ Diagnosis } & \multirow{3}{*}{$P$ value } \\
\hline & \multicolumn{2}{|c|}{ MWA } & \multicolumn{2}{|c|}{ ETTH } & \\
\hline & $\mathbf{n}$ & $\%$ & $\mathbf{n}$ & $\%$ & \\
\hline Osmophobia between headache attacks & 48 & 24.0 & 0 & 0.0 & $<0.014^{\mathrm{a}}$ \\
\hline Female & 37 & 20.3 & 0 & 0.0 & \\
\hline Male & 11 & 61.1 & 0 & 0.0 & \\
\hline
\end{tabular}

MWA: migraine without aura; ETTH: episodic tension-type headache. ap value by Chi-square test.

sum of these products was called osmophobia index (OI). The index ranged from 0 (absence of osmophobia) to 120 (very severe and daily osmophobia). As the value of this index increased, there was more intolerance to odors.

\section{Statistical analysis}

Once the information was organized in the database, the Statistical Package for Social Sciences (SPSS ${ }^{\circledR}$ ) version 17.0 for statistical analysis was used. The Chi-square test with Yates correction, Fisher's exact test and Mann-Whitney test for differences between averages of unpaired samples were used, assuming a significance level of 0.05 .

\section{Ethical aspects}

This study was approved by the Ethics in Research Involving Human Subjects Committee at the State University of Piaui, Brazil, protocol number 049/11 and the National Ethics in Research System, registry number 439715. All patients signed the informed consent form.

\section{Results}

There were 400 patients averaging $38.6 \pm 9.9$ in age $(95 \% \mathrm{CI}$ : 37.7 - 39.6$)$ and ranging from 22 to 58 years old, $219(54.7 \%)$ of whom were women, which corresponded to the sex ratio of 0.83:1 male/female.
Two hundred patients $(50.0 \%)$ were diagnosed with ETTH and $200(50.0 \%)$ with migraine without aura, whose distribution differed according to sex and age, as observed in Table 1. Tension-type headache was predominant in men, with a 4.4:1.0 ratio male/female, whereas in migraine this ration equaled 0.1:1 ratio, thus, predominantly female. The differences were significant. Regarding age, tension-type headache was present in patients aged $40.0 \pm 10.4$ years old, while migraine was diagnosed in younger patients, aged $37.3 \pm 9.0$ years old, and these differences were also significant.

In the period between attacks, there was a predominance of absence of osmophobia for both patients with migraine without aura and patients with ETTH, regardless of sex. However, when present, it was restricted to patients with migraine without aura $(48 / 200,24.0 \%)$. This difference reached statistical significance (Table 2).

After filling out the osmophobia diary for a month, we observed that the frequency of osmophobia between attacks was $15.6 \pm 6.8$ days (95\% CI: 13.7 - 17.7) in the evaluation period and in $62.5 \%(30 / 48)$ of migraine patients presenting this symptom, the frequency was greater than 15 days. Moreover, the intensity ranged from severe to very severe in $61.5 \%$ (460/748) of all episodes of osmophobia and the OI was equal to $42.3 \pm 17.93(95 \%$ CI: 37.2 - 47.4) (Table 3, 4).

\section{Discussion}

Patients with headache from different cities are referred to our Headache Center. Most patients are diagnosed with a primary headache, especially migraine. It is unusual that so many pa-

Table 3. Distribution of 748 Episodes of Osmophobia According to the Frequency and Intensity for 30 Days in 48 Migraine Patients

\begin{tabular}{|clll}
\hline \multirow{2}{*}{ Variables } & \multicolumn{3}{c}{ Episodes of osmophobia } \\
\cline { 2 - 4 } & Number of days (n, \%) & Average & $\mathbf{9 5 \% ~ C I ~}$ \\
\hline Days with osmophobia & $748(100.0)$ & $15.6 \pm 6.8$ & $13.7-17.5$ \\
Mild (VAS 1 - 4) & $117(15.6)$ & $2.4 \pm 3.4$ & $1.4-3.4$ \\
Moderate (VAS 5 - 7) & $171(22.9)$ & $3.6 \pm 3.4$ & $2.6-4.5$ \\
Severe (VAS 8 - 9) & $264(35.3)$ & $5.5 \pm 3.9$ & $4.4-6.6$ \\
Very severe (VAS 10) & $196(26.2)$ & $4.1 \pm 3.2$ & $3.2-5.0$ \\
\hline
\end{tabular}

VAS: visual analog scale. 
Table 4. Distribution of the Frequency and Intensity of Osmophobia Between Attacks for 30 Days in 48 Migraine Patients

\begin{tabular}{|c|c|c|c|c|c|c|}
\hline \multirow{2}{*}{ Patient } & \multirow{2}{*}{ Frequency (days) } & \multicolumn{4}{|c|}{ Intensity } & \multirow{2}{*}{$\mathrm{OI}^{\mathrm{a}}$} \\
\hline & & Mild (VAS 1 - 4) & Moderate (VAS 5 - 7) & Severe (VAS 8 - 9) & Very severe (VAS 10) & \\
\hline 1 & 6 & 1 & 0 & 2 & 3 & 19 \\
\hline 2 & 17 & 3 & 7 & 7 & 0 & 38 \\
\hline 3 & 23 & 4 & 4 & 5 & 10 & 67 \\
\hline 4 & 12 & 0 & 0 & 4 & 8 & 44 \\
\hline 5 & 21 & 3 & 10 & 4 & 4 & 51 \\
\hline 6 & 5 & 0 & 0 & 0 & 5 & 20 \\
\hline 7 & 18 & 2 & 3 & 8 & 5 & 52 \\
\hline 8 & 10 & 0 & 3 & 3 & 4 & 31 \\
\hline 9 & 20 & 1 & 0 & 12 & 7 & 65 \\
\hline 10 & 24 & 3 & 11 & 5 & 5 & 60 \\
\hline 11 & 5 & 0 & 0 & 0 & 5 & 20 \\
\hline 12 & 20 & 2 & 4 & 0 & 14 & 66 \\
\hline 13 & 25 & 3 & 14 & 5 & 3 & 58 \\
\hline 14 & 6 & 1 & 0 & 4 & 1 & 17 \\
\hline 15 & 10 & 0 & 0 & 0 & 10 & 40 \\
\hline 16 & 18 & 2 & 3 & 8 & 5 & 52 \\
\hline 17 & 12 & 0 & 2 & 5 & 5 & 39 \\
\hline 18 & 17 & 2 & 3 & 7 & 5 & 49 \\
\hline 19 & 10 & 0 & 0 & 8 & 2 & 32 \\
\hline 20 & 16 & 2 & 3 & 7 & 4 & 45 \\
\hline 21 & 12 & 1 & 1 & 10 & 0 & 33 \\
\hline 22 & 24 & 11 & 7 & 3 & 3 & 36 \\
\hline 23 & 16 & 4 & 3 & 9 & 0 & 37 \\
\hline 24 & 21 & 0 & 6 & 15 & 0 & 57 \\
\hline 25 & 9 & 0 & 3 & 5 & 1 & 25 \\
\hline 26 & 5 & 0 & 0 & 5 & 0 & 15 \\
\hline 27 & 24 & 3 & 10 & 6 & 5 & 61 \\
\hline 28 & 12 & 0 & 1 & 1 & 10 & 45 \\
\hline 29 & 22 & 0 & 3 & 15 & 4 & 67 \\
\hline 30 & 18 & 0 & 3 & 8 & 7 & 58 \\
\hline 31 & 18 & 2 & 3 & 8 & 5 & 56 \\
\hline 32 & 5 & 0 & 4 & 0 & 1 & 12 \\
\hline 33 & 18 & 0 & 3 & 5 & 10 & 61 \\
\hline 34 & 20 & 12 & 8 & 0 & 0 & 28 \\
\hline 35 & 10 & 4 & 1 & 5 & 0 & 21 \\
\hline 36 & 25 & 10 & 6 & 9 & 0 & 49 \\
\hline 37 & 15 & 15 & 0 & 0 & 0 & 15 \\
\hline 38 & 20 & 2 & 4 & 9 & 5 & 57 \\
\hline 39 & 16 & 2 & 3 & 7 & 4 & 45 \\
\hline 40 & 3 & 0 & 0 & 0 & 3 & 12 \\
\hline 41 & 22 & 3 & 4 & 10 & 5 & 61 \\
\hline 42 & 20 & 8 & 4 & 5 & 3 & 46 \\
\hline
\end{tabular}


Table 4. Distribution of the Frequency and Intensity of Osmophobia Between Attacks for 30 Days in 48 Migraine Patients - (Continued)

\begin{tabular}{|c|c|c|c|c|c|c|}
\hline \multirow{2}{*}{ Patient } & \multirow{2}{*}{ Frequency (days) } & \multicolumn{4}{|c|}{ Intensity } & \multirow{2}{*}{$\mathrm{OI}^{\mathrm{a}}$} \\
\hline & & Mild (VAS 1 - 4) & Moderate (VAS 5 - 7) & Severe (VAS 8 - 9) & Very severe (VAS 10) & \\
\hline 43 & 20 & 0 & 6 & 9 & 5 & 59 \\
\hline 45 & 25 & 3 & 5 & 11 & 6 & 70 \\
\hline 46 & 24 & 5 & 11 & 3 & 5 & 56 \\
\hline
\end{tabular}

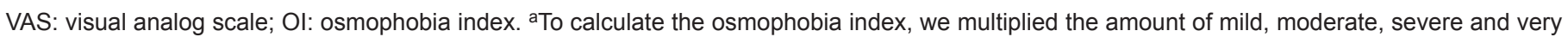
severe intensities, respectively, by the scores 1, 2, 3 and 4 .

tients with ETTH are referred for tertiary-care treatment and that this headache predominates in men, but our study design required a large population diagnosed with ETTH. In addition, our study population comprised a non-random sampling and convenience.

According to the ICHD-3 $\beta$ [21], during migraine attacks, the patient has headache accompanied by nausea and/or vomiting, photophobia and phonophobia. In addition to these symptoms, the presence of osmophobia often occurs although not diagnostic being a diagnostic criterion to the ICHD-3 $\beta[2,3$, $4,9,10,21]$. However, in the period between attacks, the migraine patient presents other symptoms such as tachycardia, constipation and osmophobia [22].

The exact mechanism of osmophobia is unknown. However a recent study showed that the olfactory processing is altered during headache attacks in migraine patients, suggesting that there are specific neuronal connections between the olfactory and trigeminal nociceptive system [23] because most odors are bimodal, i.e. they activate the trigeminal and olfactory nerves $[24,25]$. A study by fMRI during headache attacks in migraine patients and normal subjects showed increased activity of limbic system and brainstem in response to olfactory stimulation, but only in migraine patients [23].

Osmophobia is more common during migraine attacks [1, 2-7], but some studies have shown that osmophobia persists between attacks of migraine $[2,15,17,19,20]$. In chronic migraine, for example, $40.0 \%$ of patients present osmophobia in the period between attacks $[2,17]$.

In our study, osmophobia between attacks was restricted to migraine patients in a percentage of $24.0 \%$. A previous study showed that this prevalence is $35.0 \%$ [15] and that patients with migraine in the period between attacks change the threshold for olfactory stimuli $[15,20,25]$, thus osmophobia may occur in the absence of pain.

There is some difficulty in assessing the frequency and intensity of osmophobia because this symptom varies in each patient depending on the cultural, emotional and environmental experiences. In determining these parameters, the author has used in the past 10 years, the osmophobia diary, which is an important diagnostic tool for the evaluation of all characteristics inherent in osmophobia, such as association with headache, frequency and intensity.

In our study, we used a VAS to assess the intensity of osmophobia. This scale is useful because it compares a patient with himself/herself over time, but it is less reliable when comparing a patient with another [26]. It allowed us to detect that the osmophobia was severe to very severe in most of our patients.

We have identified the intensity of osmophobia, but we have not identified the duration and suffering caused by this symptom. From the knowledge of the intensity of osmophobia, we have calculated the OI. The osmophobia improvement occurs when there is a decrease in the number of days with osmophobia (frequency) and OI (intensity).

Osmophobia between headache attacks that occurred over a period of 30 days (frequency) was noted down in the osmophobia diary. The frequency of osmophobia was the sum of the number of days in which osmophobia was present. However, we cannot count intensities, especially if it varies from mild to very severe; therefore we used the OI.

There is no relationship between frequency and intensity of osmophobia. Some patients had many days with osmophobia (high frequency), but a small OI (patient 22); others had a few days with osmophobia (low frequency), but a high OI (patient 33). Thus, we can say that the highest OI means greater patient suffering. The diary will show when osmophobia is improved. In our observation, it appears that OI is associated with all features of migraine, such as nausea, photophobia, and phonophobia. We believe that this will help validate the OI as an object of study.

Currently, there is a case report showing that osmophobia disappeared when the patient was treated with sertraline [27]. We believe that as the research on osmophobia continues, it may contribute to the emergence of specific treatment for osmophobia between headache attacks in migraine patients, especially those with a high OI. Therefore, we decided to determine an OI for a better follow-up of the osmophobia between headache attacks.

When migraine patients have few headache attacks per month, but osmophobia between headache attacks is very frequent or intense, there is an ineffective prophylaxis. Hence, migraine prophylaxis should be maintained for several months until the patient becomes pain-free and shows no other symptoms, including osmophobia [28].

\section{Conclusions}

An osmophobia diary could be considered as a potentially val- 
uable tool to be applied and tested in later studies to evaluate the frequency and intensity of osmophobia between headache attacks in migraine patients.

\section{Clinical implications}

Osmophobia between headache attacks occurs in migraine patients but not in tension-type headache patients.

The knowledge of the frequency and intensity of osmophobia is important for the treatment of migraine patients.

\section{Acknowledgement}

We would like to thank teacher Joao Livio Norberto for his help with the English language.

\section{Funding}

This research received no specific grant from any funding agency in the public, commercial, or not-for-profit sectors.

\section{Conflict of Interest}

There is no conflict of interest.

\section{References}

1. Saisu A, Tatsumoto M, Hoshiyama E, Aiba S, Hirata $\mathrm{K}$. Evaluation of olfaction in patients with migraine using an odour stick identification test. Cephalalgia. 2011;31(9):1023-1028.

2. Sjostrand C, Savic I, Laudon-Meyer E, Hillert L, Lodin K, Waldenlind E. Migraine and olfactory stimuli. Curr Pain Headache Rep. 2010;14(3):244-251.

3. Zanchin G, Dainese F, Trucco M, Mainardi F, Mampreso E, Maggioni F. Osmophobia in migraine and tension-type headache and its clinical features in patients with migraine. Cephalalgia. 2007;27(9):1061-1068.

4. Zanchin G, Dainese F, Mainardi F, Mampreso E, Perin C, Maggioni F. Osmophobia in primary headaches. J Headache Pain. 2005;6(4):213-215.

5. Raieli V, Pandolfi E, La Vecchia M, Puma D, Calo A, Celauro A, Ragusa D. The prevalence of allodynia, osmophobia and red ear syndrome in the juvenile headache: preliminary data. J Headache Pain. 2005;6(4):271-273.

6. Kelman L. The place of osmophobia and taste abnormalities in migraine classification: a tertiary care study of 1237 patients. Cephalalgia. 2004;24(11):940-946.

7. Kelman L. Osmophobia and taste abnormality in migraineurs: a tertiary care study. Headache. 2004;44(10):1019-1023.

8. Silva-Neto RP, Peres MF, Valenca MM. Accuracy of osmophobia in the differential diagnosis between migraine and tension-type headache. J Neurol Sci. 2014;339(1-
2):118-122.

9. De Carlo D, Dal Zotto L, Perissinotto E, Gallo L, Gatta M, Balottin U, Mazzotta G, et al. Osmophobia in migraine classification: a multicentre study in juvenile patients. Cephalalgia. 2010;30(12):1486-1494.

10. Corletto E, Dal Zotto L, Resos A, Tripoli E, Zanchin G, Bulfoni C, Battistella PA. Osmophobia in juvenile primary headaches. Cephalalgia. 2008;28(8):825-831.

11. Vingen JV, Sand T, Stovner LJ. Sensitivity to various stimuli in primary headaches: a questionnaire study. Headache. 1999;39(8):552-558.

12. Viaro F, Maggioni F, Mampreso E, Zanchin G. Osmophobia in secondary headaches. In: Proceedings of 13th Congress of the European Federation of Neurological Societies, 2009 Sep 12-15; Florence, Italy. Eur J Neurol. 2009;16(96):1107.

13. Silva-Neto RP, Peres MF, Valenca MM. Odorant substances that trigger headaches in migraine patients. Cephalalgia. 2014;34(1):14-21.

14. Fukui PT, Goncalves TR, Strabelli CG, Lucchino NM, Matos FC, Santos JP, Zukerman E, et al. Trigger factors in migraine patients. Arq Neuropsiquiatr. 2008;66(3A):494499.

15. Demarquay G, Royet JP, Giraud P, Chazot G, Valade D, Ryvlin P. Rating of olfactory judgements in migraine patients. Cephalalgia. 2006;26(9):1123-1130.

16. Spierings EL, Ranke AH, Honkoop PC. Precipitating and aggravating factors of migraine versus tension-type headache. Headache. 2001;41(6):554-558.

17. Porta-Etessam J, Casanova I, Garcia-Cobos R, Lapena T, Fernandez MJ, Garcia-Ramos R, Serna C. [Osmophobia analysis in primary headache]. Neurologia. 2009;24(5):315-317.

18. Morillo LE, Alarcon F, Aranaga N, Aulet S, Chapman E, Conterno L, Estevez E, et al. Clinical characteristics and patterns of medication use of migraneurs in Latin America from 12 cities in 6 countries. Headache. 2005;45(2):118126.

19. Demarquay G, Royet JP, Mick G, Ryvlin P. Olfactory hypersensitivity in migraineurs: a $\mathrm{H}(2)(15) \mathrm{O}-\mathrm{PET}$ study. Cephalalgia. 2008;28(10):1069-1080.

20. Snyder RD, Drummond PD. Olfaction in migraine. Cephalalgia. 1997;17(7):729-732.

21. The International Classification of Headache Disorders, 3rd edition (beta version). Cephalalgia. 2013;33(9):629808.

22. Raffaelli Jr E, Silva-Neto RP, Roesler CP. Dor de cabeca - um guia para entender as dores de cabeca e seus tratamentos. Prestigio Editorial: Rio de Janeiro, 2005.

23. Stankewitz A, May A. Increased limbic and brainstem activity during migraine attacks following olfactory stimulation. Neurology. 2011;77(5):476-482.

24. Denuelle M, Fabre N. Functional neuroimaging of migraine. Rev Neurol (Paris). 2013;169(5):380-389.

25. Savic I, Gulyas B, Larsson M, Roland P. Olfactory functions are mediated by parallel and hierarchical processing. Neuron. 2000;26(3):735-745.

26. Sousa FF, Silva JA. A metrica da dor (dormetria): problemas teoricos e metodologicos. Revista Dor. 2005;6:469- 
513.

27. Kuo YH, Chang Y, Chen HC, Liao SC. Sertraline alleviated osmophobia caused by partial hypopituitarism with isolated ACTH deficiency. Gen Hosp Psychiatry.
2013;35(5):574 e579-510.

28. Silva-Neto RP, Almeida KJ, Bernardino SN. Analysis of the duration of migraine prophylaxis. J Neurol Sci. 2014;337(1-2):38-41. 